\title{
O IBGE e as pesquisas populacionais
}

\author{
Luiz Antonio Pinto de Oliveira* \\ Celso Cardoso da Silva Simões ${ }^{* *}$
}

\begin{abstract}
Focaliza-se o histórico dos censos demográficos, do registro civil e da Pesquisa Nacional por Amostra de Domicílios (PNAD), com ênfase nas principais questões investigadas por cada uma dessas pesquisas. Destaca-se o importante papel do Estado no desenvolvimento, principalmente, dos censos demográficos, o que explica seu desenvolvimento mais rápido, enquanto as estatísticas do registro civil ficaram dependentes, em sua fase inicial, das nem sempre estáveis relações entre o Estado e a Igreja. É mostrada a importância crescente dos censos demográficos como instrumento de análise das componentes demográficas, sendo o Censo de 1970 considerado um marco divisório, tanto no que diz respeito à organização, à riqueza de detalhes, como à confiabilidade dos números, destacando-se o papel da sociedade civil, da comunidade acadêmica e dos formuladores de políticas públicas nesse processo. Destacase também a Pesquisa Nacional por Amostra de Domicílios, realizada durante os períodos intercensitários, com múltiplos propósitos de investigação, incluindo, com periodicidade variável, características demográficas (migração, fecundidade, nupcialidade) e de saúde.
\end{abstract}

Palavras-chave: Censos. Registro civil. PNAD. População. Fecundidade. Mortalidade. Migração. Cidadania. Características socioeconômicas.

\section{Introdução}

Em sua já razoavelmente longa história, o IBGE elaborou e produziu um conjunto de pesquisas bastante significativo no que diz respeito à oferta de informações sobre as diversas características demográficas e socioeconômicas da população brasileira. Dentre essas pesquisas, o censo demográfico é um eixo de referência para todas as demais.

Uma outra pesquisa que foi muito utilizada desde o final do século XIX, sobretudo pelos órgãos de saúde pública, foi o Sistema de Estatísticas Vitais, originado das estatísticas do registro civil.

A primeira lei brasileira determinando a realização de recenseamentos nacionais de população, a cada dez anos, foi a Lei n. 1829 , sancionada em 1870 , ainda durante o Império. A mesma lei determinava, ainda, que o governo deveria organizar os sistemas de nascimentos, casamentos e óbitos, criando na capital uma Diretoria Geral de Estatística.

Até então, as estatísticas limitavam-se a registros não sistematizados e listas nominativas provinciais, com objetivos

\footnotetext{
*Coordenador de População e Indicadores Sociais do Instituto Brasileiro de Geografia e Estatística (IBGE).

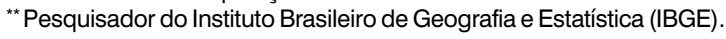


principalmente fiscais. Cabe destacar que em 1808, com a vinda da Corte portuguesa para o Brasil, foi feito um primeiro levantamento, contabilizando um total de 4 milhões de habitantes no país.

Sob os efeitos da citada lei, a Diretoria Geral de Estatística do Ministério de Negócios do Império realizou em 1872 o primeiro Censo Nacional de População. Como se vê, a série histórica dos censos brasileiros tem origem nesta decisão de governo. Porém, se os censos e a Diretoria Geral de Estatística tiveram uma institucionalização rápida e estruturada, o mesmo não se pode afirmar em relação ao registro civil.

O primeiro ato que, de certo modo, pode ser considerado relacionado ao futuro funcionamento do registro civil foi a proibição do sepultamento de pessoas sem a certidão de óbito expedida por "médico ou outro facultativo", determinada por lei datada de 1814. ${ }^{1}$ Naturalmente, os efeitos desta proibição foram restritos, em face da pequena disponibilidade desses profissionais em um país profundamente rural. No início da década de 1860, quando a imigração internacional começava a se intensificar no Brasil, foram sancionados decretos atribuindo ao Estado a regulamentação dos registros de casamentos e de óbitos de todos aqueles que não professavam a religião oficial, ou seja, a católica.

Fica, portanto, claro o papel do Estado no desenvolvimento dessas duas importantes fontes de informação demográfica. Mas, enquanto as estatísticas populacionais censitárias, desde sua origem, foram de exclusiva responsabilidade do Estado, o registro das estatísticas vitais (casamento, batismo e sepultamento), em um primeiro momento, coube principalmente à Igreja. Esta situação explica, talvez, o desenvolvimento mais rápido e eficiente dos censos demográficos, enquanto as estatísticas do registro civil ficaram dependentes das nem sempre estáveis relações entre o Estado e a Igreja.
Por outro lado, as duas fontes de informação tinham também funções distintas: se aos censos cabia produzir e fornecer as estatísticas então demandadas pelo Estado, os dados do registro civil sempre foram encarados como subproduto de uma função administrativa e legal, principalmente após a laicização dos registros públicos, a partir do governo republicano.

\section{Evolução dos censos demográficos e do registro civil}

\section{Os censos demográficos}

Os censos têm oferecido as mais amplas possibilidades para os estudos de população - sua quantificação, composição, estrutura e distribuição políticaadministrativa - e, em especial a partir do Censo de 1940, já sob a responsabilidade do IBGE (criado em 1936), para a investigação das componentes demográficas, tais como fecundidade, mortalidade e migrações internas.

O primeiro censo brasileiro, realizado, como vimos, em 1872, teve como meta "o recenseamento de todos os habitantes do Império, nacionais e estrangeiros, livres e escravos, presentes ou ausentes, em $1^{\circ} \mathrm{de}$ agosto de 1872".

Por problemas políticos, deixou-se de realizar o censo em 1880. Os censos de 1890 e 1900 apresentaram-se bastante problemáticos quanto à sua cobertura $\mathrm{e}$ qualidade.

Em 1910 e 1930, também por questões políticas, não foram realizados os respectivos censos. O Censo Demográfico de 1920 , muito rico em detalhes, teria sobreestimado em cerca de $10 \%$ a população, de acordo com avaliações posteriores feitas por Giorgio Mortara.

Com o Censo de 1940 o Brasil inicia uma nova etapa da história das estatísticas populacionais, sobretudo no que se refere à dinâmica demográfica, graças ao esforço e conhecimento do demógrafo italiano emigrado para o Brasil, Giorgio Mortara.

\footnotetext{
${ }^{1}$ Registro Civil 1961. Ministério da Justiça e Negócios Interiores, Rio de Janeiro, 1963.
} 
Atendendo aos padrões internacionais da época, visando à uniformidade e comparabilidade dos resultados com outras nações, objetivos que de certo modo já estavam presentes nas preocupações dos responsáveis pelo planejamento do Censo de 1940, o Brasil participa, em 1946, do programa de censos simultâneos proposto pelo Comitê do Censo das Américas.

Importante ressaltar que com os censos de 1940 e 1950 são criadas as condições para que se iniciem, efetivamente, os estudos demográficos abrangendo o conjunto do país. Nesse processo, Mortara desempenhou papel importantíssimo, dada a repercussão de seus artigos, publicados pelo IBGE, nos meios científicos e entre os pesquisadores da área de demografia na América Latina.

A partir de 1960, em função do aumento dos custos devido ao extraordinário crescimento da população brasileira desde os anos 30, o IBGE reorganizou o questionário de coleta do censo, criando um questionário básico, para ser respondido pelo universo dos domicílios, e um questionário mais amplo e detalhado para uma fração de amostra correspondente a $25 \%$ dos domicílios.

Em decorrência de crises internas e da instabilidade política do país no início dos anos 60 , os resultados censitários completos não foram divulgados durante a década; somente em 1978, e apenas parcialmente, eles se tornaram públicos.

O Censo de 1970 é considerado um marco divisório na história dos censos demográficos brasileiros, tanto no que diz respeito à organização, à riqueza de detaIhes, como à confiabilidade dos números. Seus resultados foram amplamente analisados durante a década de 70 e até o início dos anos 80. Nesse período, o mundo acadêmico e científico, inclusive nas chamadas ciências sociais, havia se fortalecido e consolidado, com grande crescimento de instituições voltadas para a análise e pesquisa. Temas como distribuição de renda, mercado de trabalho e educação foram exaustivamente estudados, não só em nível nacional como, principalmente, com ênfase nas expressivas desigualdades regionais.
No campo dos estudos demográficos, instituições públicas e centros de pesquisa envolveram-se com as informações relativas ao crescimento populacional - a chamada "explosão demográfica" - e aos níveis de fecundidade e, de forma bastante intensa, buscaram um diagnóstico e a mensuração dos fluxos e características dos movimentos migratórios, tradicionais e novos. Em se tratando de um momento inicial do processo de informatização das informações, o IBGE recebeu, ao longo da década, um grande número de pedidos de tabulações especiais com cruzamentos de variáveis socioeconômicas e demográficas específicas para os vários estudos então realizados.

Os censos de 1980 e 1991 ampliaram a riqueza da investigação dos censos anteriores, apesar de algumas dificuldades momentâneas enfrentadas, especialmente o Censo de 1991, adiado por força das crises fiscais e políticas da virada dos anos 80 para os 90 .

O período que antecedeu e aquele que se seguiu ao Censo de 1991 foram fortemente marcados pelas demandas da sociedade e pelo início da discussão sobre a produção de estatísticas tanto com a sociedade civil como entre os formuladores das políticas públicas. O IBGE estimulou e propiciou essa discussão com amplos setores sociais, da qual resultaram, inicialmente, a reformulação de alguns itens constantes do questionário de 1991 e a incorporação de novos no Censo de 2000. A participação cada vez maior da sociedade e a importantíssima contribuição dos governos municipais e estaduais e de empresas de serviço público na preparação da malha cartográfica básica para os trabalhos dos recenseadores são um reflexo dessa tendência. Hoje, em tese, o IBGE está muito mais aberto às demandas da sociedade, tanto em relação aos censos como às pesquisas conjunturais $e$ estruturais.

Entretanto, a persistência de dificuldades econômicas, que se vêm tornando sistemáticas, tem direcionado o IBGE a procurar alternativas na área da informática, seja disponibilizando aos principais 
usuários das informações censitárias as tabulações básicas em meio magnético (CD), seja criando processos e regras para acesso ao microdado, mantidas as recomendações relativas ao sigilo. A Internet também tem sido uma outra alternativa para viabilizar a democratização do acesso às informações, não só dos censos mas também das demais pesquisas da instituição.

O Quadro 1 permite melhor entendimento e percepção da evolução no conteúdo dos temas e quesitos investigados na série dos censos demográficos.

QUADRO 1

Evolução dos dados coletados nos censos demográficos de 1872, 1890, 1900, 1940, 1950, 1960, 1970, 1980, 1991 e 2000

\begin{tabular}{|c|c|c|c|c|c|c|c|c|c|c|c|}
\hline Dados coletados & $\begin{array}{r}1 / 8 / \\
1872\end{array}$ & $\begin{array}{c}21 / 12 / \\
1890\end{array}$ & $\begin{array}{c}31 / 12 / \\
1900\end{array}$ & $\begin{array}{c}1 / 9 / \\
1920\end{array}$ & $\begin{array}{c}1 / 7 / \\
1940\end{array}$ & $\begin{array}{r}1 / 7 / \\
1950\end{array}$ & $\begin{array}{c}1 / 9 / \\
1960\end{array}$ & $\begin{array}{c}1 / 9 / \\
1970\end{array}$ & $\begin{array}{c}1 / 9 / \\
1980\end{array}$ & $\begin{array}{c}1 / 9 / \\
1991\end{array}$ & $\begin{array}{c}1 / 8 / \\
2000\end{array}$ \\
\hline \multicolumn{12}{|c|}{$\begin{array}{l}\text { 1. Identificação, Condição } \\
\text { de Presença e Loc. Geográfica }\end{array}$} \\
\hline 1.1. Nome & $x$ & $x$ & $x$ & $x$ & $x$ & $x$ & $x$ & $x$ & $\mathrm{x}$ & $x$ & $x$ \\
\hline 1.2. População Presente & $x$ & $x$ & $x$ & $x$ & $x$ & $x$ & $x$ & $x$ & $x$ & $x$ & $x$ \\
\hline 1.3. População Residente & - & - & - & - & $x$ & $x$ & $x$ & $x$ & $x$ & $x$ & $x$ \\
\hline \multicolumn{12}{|l|}{ 1.4. Dados sobre a Localização } \\
\hline Geográfica & $\mathrm{x}$ & $x$ & $x$ & $\mathrm{x}$ & $x$ & $x$ & $x$ & $x$ & $x$ & $x$ & $x$ \\
\hline \multicolumn{12}{|l|}{ 2. Informações Pessoais } \\
\hline 2.1. Sexo & $x$ & $x$ & $x$ & $x$ & $x$ & $x$ & $x$ & $x$ & $x$ & $x$ & $x$ \\
\hline 2.2. Idade & $x$ & $x$ & $x$ & $x$ & $x$ & $x$ & $x$ & $x$ & $x$ & $x$ & $x$ \\
\hline 2.3. Estado Civil & $x$ & $x$ & $x$ & $x$ & $x$ & $\mathrm{x}$ & $x$ & $x$ & $x$ & $x$ & $\mathrm{x}$ \\
\hline 2.4. Nacionalidade & $x$ & $x$ & $x$ & $x$ & $x$ & $x$ & $x$ & $x$ & $x$ & $x$ & $x$ \\
\hline 2.5. Lugar de Nascimento & $x$ & $x$ & $x$ & $x$ & $x$ & $x$ & $x$ & $x$ & $x$ & $x$ & $\mathrm{x}$ \\
\hline 2.6. Data de Nascimento & - & - & - & - & $x$ & $x$ & $x$ & $x$ & $x$ & $x$ & $x$ \\
\hline 2.7. Filiação (Legal ou llegal) & - & $x$ & $x$ & - & - & - & - & - & - & - & - \\
\hline 2.8. Cor & $x$ & $x$ & - & - & $x$ & $x$ & $x$ & - & - & $x$ & $x$ \\
\hline
\end{tabular}

3. Informações Econômicas

3.1. Ocupação, Profissão ou Cargo

3.2. Ramo de Atividade

3.3. Posição na Ocupação

3.4. Rendimento

3.5. Desemprego

3.6. Ocupação Suplementar

3.7. Horas Trabalhadas

3.8. Contribuição à Previdência

3.9. Local do Trabalho

$\begin{array}{lllllllllll}- & \mathrm{X} & \mathrm{X} & \mathrm{X} & \mathrm{X} & \mathrm{X} & \mathrm{X} & \mathrm{X} & \mathrm{X} & \mathrm{X} & \mathrm{X} \\ - & - & - & \mathrm{X} & \mathrm{X} & \mathrm{X} & \mathrm{X} & \mathrm{X} & \mathrm{X} & \mathrm{X} & \mathrm{X} \\ - & - & - & - & \mathrm{X} & \mathrm{X} & \mathrm{X} & \mathrm{X} & \mathrm{X} & \mathrm{X} & \mathrm{X} \\ - & - & - & - & - & - & \mathrm{X} & \mathrm{X} & \mathrm{X} & \mathrm{X} & \mathrm{X} \\ - & - & - & - & - & - & \mathrm{X} & \mathrm{X} & \mathrm{X} & \mathrm{X} & \mathrm{X} \\ - & - & - & - & \mathrm{X} & \mathrm{X} & - & - & - & - & \mathrm{X} \\ - & - & - & - & - & - & - & \mathrm{X} & \mathrm{X} & \mathrm{X} & \mathrm{X} \\ - & - & - & - & - & - & - & - & \mathrm{X} & \mathrm{X} & \mathrm{X} \\ - & - & - & - & - & - & - & - & - & \mathrm{X} & \mathrm{X}\end{array}$

\section{Informações sobre o Domicílio e a}

Família

4.1. Parentesco ou Relação com

$$
\text { o Chefe }
$$

4.2. Tipos de Família

4.3. Características Físicas do Domicílio

4.4. Características Gerais do Domicílio

4.5. Condições de Ocupação do Domicílio

4.6. Valor do Aluguel

4.7. Tempo de Residência no Domicílio

\begin{tabular}{|c|c|c|c|c|c|c|c|c|c|}
\hline$X$ & $X$ & $X$ & - & $X$ & $X$ & $X$ & $X$ & $X$ & $X$ \\
\hline - & - & - & - & - & - & - & $X$ & $x$ & $x$ \\
\hline- & - & - & $x$ & $X$ & $x$ & $x$ & $x$ & $x$ & $x$ \\
\hline - & - & - & - & $x$ & $X$ & $x$ & $x$ & $x$ & $x$ \\
\hline - & - & - & $x$ & $X$ & $X$ & $X$ & $X$ & $x$ & $x$ \\
\hline - & - & - & - & $X$ & $X$ & $x$ & $x$ & $x$ & $x$ \\
\hline- & - & - & - & - & - & - & $X$ & $x$ & $x$ \\
\hline
\end{tabular}


(continuação)

$\begin{array}{lccccccccccc}\text { Dados coletados } & 1 / 8 / & 21 / 12 / & 31 / 12 / & 1 / 9 / & 1 / 7 / & 1 / 7 / & 1 / 9 / & 1 / 9 / & 1 / 9 / & 1 / 9 / & 1 / 8 / \\ & 1872 & 1890 & 1900 & 1920 & 1940 & 1950 & 1960 & 1970 & 1980 & 1991 & 2000\end{array}$

5. Informações sobre a

Nupcialidade, Fecundidade

e Mortalidade

5.1. Tipo de União

5.2. Ano de Casamento ou União

5.3. Total de Filhos Tidos

5.4. Filhos Tidos Nascidos Vivos

5.5. Filhos Tidos Nascidos Mortos

5.6. Filhos Sobreviventes

5.7. Filhos Tidos no Ano Anterior

(Nascidos Vivos e Nascidos Mortos)

5.8. Data de Nascimento do Último Filho

Nascido Vivo

5.9. Tem Mãe Viva?

\section{Informações sobre Educação}

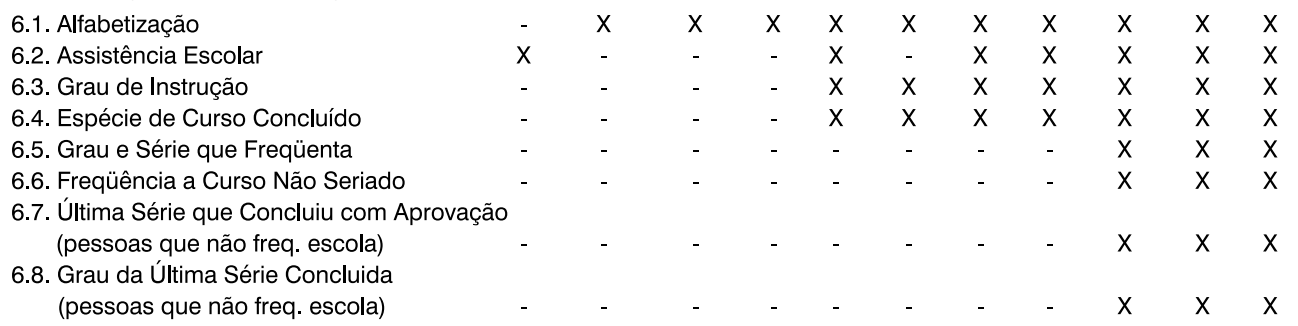

\section{Informações sobre Migrações}

7.1. Tempo de Residência na Localidade Atual

7.2. Local de Residência Anterior

7.3. Situação de Residência no Município de Nascimento

7.4. Situação de Residência no Município Anterior

7.5. Tempo de Residência no Município

7.6. Local de Moradia (UF e Município ) a 10 anos atrás

7.7. Local de Moradia (UF e Município ) a 5 anos atrás

7.9. Migração Pendular

\begin{tabular}{lllllllllll}
- & - & - & - & - & - & $\mathrm{x}$ & $\mathrm{x}$ & $\mathrm{x}$ & $\mathrm{x}$ & $\mathrm{x}$ \\
- & - & - & - & - & - & $\mathrm{x}$ & $\mathrm{x}$ & $\mathrm{x}$ & $\mathrm{x}$ & $\mathrm{x}$ \\
- & - & - & - & - & - & - & - & $\mathrm{x}$ & $\mathrm{x}$ & - \\
& & & & & & & & & & \\
- & - & - & - & - & - & - & - & $\mathrm{x}$ & $\mathrm{x}$ & $\mathrm{x}$ \\
- & - & - & - & - & - & - & - & $\mathrm{x}$ & $\mathrm{x}$ & $\mathrm{x}$ \\
- & - & - & - & - & - & - & - & $\mathrm{x}$ & $\mathrm{x}$ & - \\
- & - & - & - & - & - & - & - & - & $\mathrm{x}$ & $\mathrm{x}$ \\
- & - & - & - & - & - & - & - & $\mathrm{x}$ & - & $\mathrm{x}$ \\
\hline
\end{tabular}

\section{Outra Informações}

\begin{tabular}{llllllllllllll} 
8.1. Idioma & - & - & - & - & $\mathrm{X}$ & $\mathrm{X}$ & - & - & - & - & - \\
8.2. Religião & $\mathrm{X}$ & $\mathrm{X}$ & $\mathrm{X}$ & - & $\mathrm{X}$ & $\mathrm{X}$ & $\mathrm{X}$ & $\mathrm{X}$ & $\mathrm{X}$ & $\mathrm{X}$ & $\mathrm{X}$ \\
8.3. Incapacidade Física & $\mathrm{X}$ & $\mathrm{X}$ & $\mathrm{X}$ & $\mathrm{X}$ & $\mathrm{X}$ & - & - & - & - & $\mathrm{X}$ & $\mathrm{X}$ \\
\hline
\end{tabular}

Fonte: Conselho Nacional de Estatística - Serviço Nacional de Recenseamento, Legislação Básica dos Recensamentos de 1872 , 1890, 1990 e 1920. Documento Censitário, Série A, n. 2, Rio de Janeiro, 1951, IBGE. Censos Demográficos de 1940, 1950, 1960, 1970, 1980, 1991 e 2000.

\section{Registro civil}

Da mesma forma que os censos demográficos, as estatísticas do registro civil são um importante instrumento de acompanhamento dos movimentos de dinâmica demográfica que se processam dentro do país, em seus distintos níveis de desagregação geográfica.

Um sistema de boa qualidade - como acontece na totalidade dos países mais desenvolvidos e mesmo em outros não tão desenvolvidos, mas que têm preocupações com questões relacionadas à 
cidadania (p. ex., acesso universal de seus cidadãos ao documento básico, que é a certidão de nascimento) - possibilita a realização de estudos e análises, em tempo real, das principais componentes demográficas (natalidade e mortalidade), das mudanças nas estruturas familiares $e$, naqueles países que têm o sistema de registro único, até o acompanhamento dos movimentos migratórios de suas populações.

Nestas circunstâncias ideais, é bom que se o diga, muitas das questões que hoje em dia são investigadas no Brasil em censos demográficos e pesquisas domiciliares tornar-se-iam desnecessárias, com conseqüências positivas em termos de redução de custos, na medida em que haveria uma redução importante no conteúdo dos questionários.

A evolução do registro civil foi marcada por acontecimentos políticos e alterações administrativas e culturais que o afetaram diretamente.

Criado em 1888, no final do Império, o Registro Civil de Pessoas Naturais sofreu mudanças após a proclamação da República, em 1889, uma vez que alguns dos dispositivos da lei de sua criação contrariavam princípios constitucionais republicanos.

Assim, antes mesmo de ser posta em prática, a primeira lei que regulamenta 0 registro de nascimentos, casamentos e óbitos sofreu reformas. Uma das principais alterações foi a introdução da pergunta sobre cor, com a seguinte justificativa: "O Brasil foi sempre um país em que predominou a raça preta, principalmente até 1888, quando foi a mesma redimida do jugo horrível de um governo prepotente [...]". Logo, de acordo com a Diretoria Geral de Estatística, a cor deveria ser investigada em todas as estatísticas: censos e registro civil.

Em termos históricos, o processo de coleta das informações do registro civil seguiu os seguintes passos:

1. Numa primeira etapa, os cartórios enviavam diretamente à Diretoria Geral de Estatística os mapas contendo os dados de nascimentos, óbitos e casamentos registrados;

2. Posteriormente, esta função ficou a cargo dos Departamentos de Estatística dos estados, que recebiam a informação dos cartórios e a remetiam à Direção Geral de Estatística;

3. Esta intermediação foi abolida em 1973 pela Lei 6.015, que determinou a centralização da coleta dos dados vitais pelo IBGE.

Esta lei, que entrou em vigor em 1으 de janeiro de 1976, estabelecia normas sobre os registros públicos relativos ao:

- Registro Civil de Pessoas Naturais;

- Registro Civil de Pessoas Jurídicas;

- Registro de Títulos de Documentos;

- Registro de Imóveis.

A publicidade dos registros públicos é uma determinação legal. Os oficiais e os encarregados das repartições em que se fazem os registros são obrigados a lavrar certificados (atas) do que Ihes foi requerido e oferecer às partes as informações solicitadas.

Qualquer pessoa pode requerer certificado de registro civil sem informar ao oficial ou ao funcionário o motivo do pedido. Os certificados do Registro Civil de Pessoas Naturais mencionarão, sempre, a data em que foi lavrado o assentamento. Os certificados de nascimento mencionarão, além da data em que foi feito o registro, a data do nascimento e o lugar de ocorrência. Sempre que haja qualquer alteração posterior ao ato cujo certificado é solicitado, deverá o oficial mencioná-la obrigatoriamente, não obstante as especificações do pedido, sob pena de responsabilidade civil e penal.

Até 1997, o registro civil e o respectivo certificado não eram cobrados para as pessoas comprovadamente pobres. Em dezembro do mesmo ano foi aprovada a Lei 9.534, que determinou a gratuidade do registro civil de pessoas naturais a todos os brasileiros.

O registro de nascimentos deverá ser realizado dentro do prazo máximo de 15 
dias, contado a partir de seu acontecimento, prazo que pode ser estendido por três meses, para aquelas situações em que os lugares distam mais de $30 \mathrm{~km}$ da sede do cartório, não estando obrigados a essa inscrição somente os índios não integrados, podendo esta ser feita em livro próprio do órgão federal de assistência ao indígena, no caso, a Funai. As declarações de nascimento feitas após o prazo legal estão sujeitas a multa.

É obrigatória a apresentação no cartório do boletim de ocorrência do evento. No caso em que o nascimento foi domiciliar, a legislação estabelece que o responsável tem que fazer uma comunicação sobre o nascimento a uma unidade de saúde, que então emitirá o boletim de ocorrência.

O assentamento de nascimento deverá conter:

- o dia, mês, ano e lugar do nascimento, a hora exata ou aproximada do evento e o número do registro;

- o sexo do registrado;

- a natureza do parto (o fato de ser gêmeo, quando assim haja acontecido);

- o nome e sobrenome que haja sido posto na criança;

- a declaração de que a criança nasceu morta ou morreu no ato ou em seguida ao parto;

- os nomes e sobrenomes dos avós paternos e maternos.

Quanto ao registro de óbito, é importante lembrar que, em termos legais, o mesmo é precondição para qualquer sepultamento.

O registro de óbito deverá conter:

- a hora, se for possível, dia, mês e ano do falecimento;

- o lugar do falecimento, com indicação precisa;

- o sobrenome, nome, sexo, cor, estado civil, profissão, naturalidade, domicílio e residência do morto;

- se casado, o nome do cônjuge sobrevivente, mesmo quando desquitado/ divorciado; se viúvo, o nome do cônjuge já falecido e o cartório onde se realizou o matrimônio em ambos os casos;

- os nomes, sobrenomes, profissão, naturalidade e residência dos pais;

- se faleceu com testamento conhecido;

- se deixou filhos, o nome e a idade de cada um;

- se a morte foi natural ou violenta, e a causa conhecida;

- o lugar do sepultamento;

- se deixou bens e herdeiros menores ou interditados;

- se era eleitor.

O Quadro 2 apresenta a evolução dos temas e quesitos arrolados na certidão dos registros.

Complementando as informações relativas às estatísticas vitais, o registro civil investiga e fornece também informações sobre óbitos fetais.

O formulário de óbitos fetais é muito parecido com o de nascidos vivos. Apenas difere deste no fato de não incluir a data de ocorrência do evento e de agregar a informação correspondente à duração da gestação (menos de 20 semanas, de 20 a 27 semanas e mais de 27 semanas). Esta discriminação permite a identificação dos chamados óbitos tardios, ou seja, aqueles que ocorreram após 27 semanas de gestação e que são classificados como nascidos mortos.

Finalmente, as uniões legais também fazem parte do elenco de informações do registro civil. Entretanto, o registro de matrimônios não é obrigatório. Muitas uniões se dão à margem do sistema legal e só podem ser investigadas por meio de pesquisas censitárias ou domiciliares. Também existem as uniões religiosas, cujo registro fica a cargo da instituição eclesiástica, ainda que não sejam reconhecidas judicialmente.

O IBGE também investiga, nas Varas de Família, os divórcios e separações judiciais. O registro dos mesmos se dá depois de sua decretação pelos juízes das Varas de Família ou de seu encaminhamento para notificação no cartório onde se realizou ou 
QUADRO 2

Registro civil, 1888-2004 - Nascimementos

\begin{tabular}{|c|c|c|c|c|c|c|}
\hline \multirow{2}{*}{ Informações } & \multicolumn{4}{|c|}{$\begin{array}{l}\text { Evolução das Informações Estabelecidas } \\
\text { por Lei no Ato do Registro de Nascimentos }\end{array}$} & \multirow{2}{*}{$\begin{array}{c}\text { Dados Coletados } \\
\text { a Nível Nacional } \\
\text { pelo IBGE a } \\
\text { partir de } 1974 \\
\text { até } 1989 \\
\text { Mapa de } \\
\text { Nascidos Vivos } \\
\text { (Modelo CBED-1) }\end{array}$} & \multirow{2}{*}{$\begin{array}{c}\text { Dados Coletados } \\
\text { a Nível Nacional } \\
\text { pelo IBGE a } \\
\text { partir de } 1990 \\
\\
\\
\text { Mapa de } \\
\begin{array}{l}\text { Nascidos Vivos } \\
\text { (Modelo RC-1) }\end{array}\end{array}$} \\
\hline & $\begin{array}{c}\text { Decreto } \\
n^{\circ} 9.883 \text { de } \\
07 / 03 / 1888\end{array}$ & $\begin{array}{c}\text { Decreto } \\
n^{\circ} 18.542 \text { de } \\
24 / 12 / 1928\end{array}$ & $\begin{array}{c}\text { Decreto } \\
n^{\circ} 4.857 \text { de } \\
9 / 11 / 1939\end{array}$ & $\begin{array}{c}\text { Lei de } \\
30 / 12 / 1973\end{array}$ & & \\
\hline \multicolumn{7}{|l|}{ 1. Dados do Registro } \\
\hline 1.1. Data & $x$ & $x$ & $x$ & $\mathrm{x}$ & $x$ & $x$ \\
\hline $\begin{array}{l}\text { 1.2. Local } \\
\text { (distrito, subd., etc.) }\end{array}$ & $x$ & $\mathrm{X}$ & $\mathrm{X}$ & $\mathrm{x}$ & $\mathrm{X}$ & $\mathrm{X}$ \\
\hline 1.3. Número do Registro & $x$ & $x$ & $x$ & $x$ & $x$ & $x$ \\
\hline \multicolumn{7}{|l|}{ 2. Dados sobre o Nascido } \\
\hline 2.1. Nome e Sobrenome & $x$ & $\mathrm{x}$ & $x$ & $x$ & - & - \\
\hline 2.2. Data de Nascimento & $x$ & $x$ & $x$ & $x$ & $\mathrm{x}$ & $\mathrm{X}$ \\
\hline $\begin{array}{l}\text { 2.3. Lugar do Nascimento } \\
\text { (Geográfico e Funcional) }\end{array}$ & $x$ & $\mathrm{x}$ & $\mathrm{X}$ & $\mathrm{X}$ & $\mathrm{X}$ & $\mathrm{X}$ \\
\hline 2.4. Sexo & $\mathrm{x}$ & $\mathrm{x}$ & $\mathrm{x}$ & $x$ & $\mathrm{x}$ & $\mathrm{x}$ \\
\hline \multicolumn{7}{|l|}{ 2.5. Natureza do Parto } \\
\hline (Gêmeos, Sim ou Não) & $x$ & $x$ & $x$ & $x$ & $x$ & $\mathrm{x}$ \\
\hline \multicolumn{7}{|l|}{ 2.6. Filiação (Legítima ou } \\
\hline llegítima) & $x$ & $x$ & $x$ & - & $\mathrm{x}$ & - \\
\hline 2.7. Estado Civil & - & - & - & - & - & $\mathrm{X}$ \\
\hline 2.8. Cor & - & $x$ & $x$ & $x$ & - & - \\
\hline \multicolumn{7}{|l|}{ 2.9. Nasceu Vivo, Nasceu } \\
\hline \multicolumn{7}{|l|}{ Morto, Morreu no Ato ou } \\
\hline Logo depois do Parto & $x$ & $x$ & $\mathrm{X}$ & $x$ & $(*)$ & $\left({ }^{\star}\right)$ \\
\hline 2.10. Local do Nascimento & - & - & - & - & - & $x$ \\
\hline \multicolumn{7}{|l|}{ 3. Dados sobre os Pais } \\
\hline 3.1. Nome & $x$ & $x$ & $x$ & $x$ & - & - \\
\hline 3.2. Naturalidade & $x$ & $x$ & $x$ & $x$ & $x$ & $x$ \\
\hline 3.3. Profissão & $x$ & $x$ & $x$ & $x$ & - & - \\
\hline 3.4. Residência & $x$ & $x$ & $x$ & $x$ & $x$ & $x$ \\
\hline 3.5. Local do Casamento & $\mathrm{x}$ & $x$ & $x$ & $x$ & - & - \\
\hline \multicolumn{7}{|l|}{ 3.6. Idade da Mãe no } \\
\hline Momento do Parto & - & - & - & - & $\mathrm{X}$ & $\mathrm{X}$ \\
\hline
\end{tabular}

\section{Outros Dados}

4.1. Ordem de Filiação de

$\begin{array}{lllll}\text { Outros Irmãos de Mesmo } & X & X & X & X\end{array}$

Sobrenome

4.2. Nome dos Avós Materno

$\begin{array}{llll}\text { e Paterno } & X & X & X\end{array}$

4.3. Nome, Sobrenome,

Profissão e Residência

das Testemunhas

$\mathrm{X}$

$\mathrm{X}$

$\mathrm{X}$

$\mathrm{X}$

(*) Esta informação é coletada no mapa de nascidos mortos/ou óbitos fetais, com as demais informações. 
QUADRO 3

Registro civil, 1888-2004-Óbitos

\begin{tabular}{|c|c|c|c|c|c|c|}
\hline \multirow{2}{*}{ Informações } & \multicolumn{4}{|c|}{$\begin{array}{l}\text { Evolução das Informações Estabelecidas } \\
\text { por Lei no Ato do Registro de Óbitos }\end{array}$} & \multirow{2}{*}{\begin{tabular}{|} 
Dados Coletados \\
a Nível Nacional \\
pelo IBGE a \\
partir de 1974 \\
até 1989 \\
Mapa de \\
Óbitos \\
(Modelo CBED-3)
\end{tabular}} & \multirow{2}{*}{\begin{tabular}{|c|} 
Dados Coletados \\
a Nível Nacional \\
pelo IBGE a \\
partir de 1990 \\
Mapa de \\
Óbitos \\
(Modelo RC-3)
\end{tabular}} \\
\hline & $\begin{array}{l}\text { Decreto } \\
n^{\circ} 9.883 \text { de } \\
07 / 03 / 1888\end{array}$ & $\begin{array}{c}\text { Decreto } \\
n^{\circ} 18.542 \text { de } \\
24 / 12 / 1928\end{array}$ & $\begin{array}{l}\text { Decreto } \\
n^{\circ} 4.857 \text { de } \\
9 / 11 / 1939\end{array}$ & $\begin{array}{c}\text { Lei de } \\
30 / 12 / 1973\end{array}$ & & \\
\hline
\end{tabular}

\section{Dados do Registro}

\begin{tabular}{|c|c|c|c|c|c|c|}
\hline 1.1. Data & $x$ & $x$ & $\mathrm{x}$ & $x$ & $x$ & $x$ \\
\hline 1.2. Local (distrito, subd., etc.) & $x$ & $x$ & $\mathrm{x}$ & $\mathrm{X}$ & $\mathrm{x}$ & $\mathrm{x}$ \\
\hline 1.3. Número do Registro & $x$ & $x$ & $\mathrm{X}$ & $\mathrm{x}$ & $x$ & $\mathrm{x}$ \\
\hline
\end{tabular}

\section{Dados sobre o Óbito}

\subsection{Nome e Sobrenome}

2.2. Data do Falecimento

2.3. Lugar do Falecimento

(Geográfico e Funcional)

\subsection{Sexo}

2.5. Idade

2.6. Estado Civil

2.7. Cor

2.8. Profissão

2.9. Naturalidade

$x \quad x$

$x \quad x \quad x$

$\begin{array}{ll}x & x \\ x & x\end{array}$

$x$
$x$

$\begin{array}{ll}- & - \\ x & x\end{array}$

2.10. Lugar de Domicílio ou

Residência do Morto

\subsection{Filiação}

$\begin{array}{llll}x & x & x & x \\ x & x & x & x \\ x & x & x & x \\ x & x & x & x \\ - & x & x & x \\ x & x & x & x \\ x & x & x & \end{array}$

$\begin{array}{lll}\mathrm{X} & \mathrm{X} & \mathrm{X} \\ \mathrm{X} & \mathrm{X} & \mathrm{X} \\ \mathrm{X} & \mathrm{X} & \mathrm{X} \\ \mathrm{X} & \mathrm{X} & \mathrm{X} \\ \mathrm{X} & - & - \\ \mathrm{X} & - & - \\ \mathrm{X} & \mathrm{X} & \mathrm{X}\end{array}$

3. Dados sobre os Pais

3.1. Nome e Sobrenome

3.2. Naturalidade

3.3. Profissão

3.4. Residência

\begin{tabular}{llllll}
$x$ & $x$ & $x$ & $x$ & $x$ & $x$ \\
$x$ & $x$ & $x$ & $x$ & - & - \\
\hline
\end{tabular}

\section{Outros Dados}

4.1. Tipo de Morte

4.2. Causa da Morte

4.3. Lugar do Sepultamento

4.4. Nome do Cônjuge e Cartório

do Casamento

$\begin{array}{lll}x & x & x \\ x & x & x \\ x & x & x \\ x & x & x\end{array}$

$\begin{array}{ll}x & x \\ x & x \\ X & x \\ x & x\end{array}$

4.5. Se Deixou Bens ou Herdeiros

Menores e Interditos

$\begin{array}{llll}x & x & x & x \\ x & x & x & x \\ x & x & x & x \\ x & x & x & x \\ X & x & x & x\end{array}$

foi registrado o matrimônio. A falta de notificação não caracteriza a ruptura do vínculo.

\section{As Pesquisas Domiciliares por Amostra de Domicílios}

\section{Histórico}

Uma outra fonte de informações que tem sido de suma importância nos estudos e análises da dinâmica demográfica do país é a Pesquisa Nacional por Amostra de Domicílios (PNAD). Esta pesquisa, implantada progressivamente no Brasil a partir de 1967, por ter propósitos múltiplos, investiga diversas características demográficas e socioeconômicas, umas de caráter permanente nas pesquisas, como as características gerais da população, educação, trabalho, rendimento e habitação, e outras com 
periodicidade variável, como as características sobre migração, fecundidade, nupcialidade, saúde, nutrição e outros temas que são incluídos no sistema de acordo com as necessidades de informação para o país.

Inicialmente, os resultados apresentados pela PNAD tinham periodicidade trimestral. A partir de 1971 os levantamentos passaram a ser anuais, com a realização da pesquisa no último trimestre. A PNAD foi interrompida para a realização dos Censos Demográficos de 1970, 1980, 1991 e 2000.

$\mathrm{Na}$ década de 70 , os principais temas investigados na PNAD, além de aspectos gerais da população, educação, trabalho, rendimento e domicílio, foram migração, fecundidade, habitação e cor. Em 19741975 foi levada a efeito uma pesquisa especial denominada Estudo Nacional da Despesa Familiar (Endef), que, além dos temas anteriores, investigou o consumo alimentar e os orçamentos familiares. Durante a realização do Endef o levantamento básico da PNAD foi interrompido.

As pesquisas realizadas na década de 80 mantiveram inalteradas as características do levantamento básico, visando, com isso, gerar uma série histórica de resultados. A única alteração ocorrida foi a incorporação definitiva na pesquisa básica dos quesitos sobre a cor das pessoas, a partir de 1987, e sobre a existência de rádio e televisão nos domicílios particulares permanentes, a partir de 1988. Por meio de pesquisas suplementares foram investigados os seguintes temas: saúde em 1981; educação em 1982; mão-de-obra e previdência em 1983; fecundidade em 1984; situação do menor em 1985; anticoncepção, acesso a serviços de saúde, suplementação alimentar e associativismo em 1986; participação político-social e estoque de aparelhos utilizadores de energia em 1988; e trabalho em 1989 e 1990.

Ao final da década de 80 e início dos anos 90 o IBGE promoveu uma ampla discussão interna e externa com vistas à reformulação e atualização do conteúdo e instrumentos de pesquisa da PNAD. A partir da PNAD de 1992, em função dessa reformulação, aprofundaram-se algumas questões referentes à investigação, principalmente, sobre trabalho e rendimento, incluindo-se no corpo básico da pesquisa, além dos aspectos gerais da população, educação e domicílio, blocos de quesitos que investigam a migração, fecundidade e nupcialidade da população. Este modelo do corpo básico da pesquisa, em linhas gerais, foi mantido durante os anos 90 , à exceção de 1994, quando a PNAD deixou de ir a campo.

Vale salientar que a partir da PNAD de 1992, para captar determinados grupos de pessoas envolvidas em atividades econômicas que anteriormente não eram incluídas na população ocupada, o conceito de trabalho e força de trabalho tornou-se mais abrangente, incluindo, por exemplo, as pessoas que trabalhavam para autoconsumo e em construção para o próprio uso, além daquelas enquadradas na posição de ocupações não remuneradas, para as quais passou a se aceitar uma carga horária mínima de apenas 1 hora semanal, quando anteriormente o limite mínimo era de 15 horas.

A extensão e profundidade da pesquisa básica determinaram que não houvesse suplementos temáticos em 1992, 1993 e 1995. Em 1996, para possibilitar a inclusão do tema suplementar mobilidade social, foram retirados três tópicos da pesquisa básica: trabalho das crianças de 5 a 9 anos de idade, ensino supletivo e nupcialidade. Em 1998, por solicitação do Ministério da Saúde, foi elaborado e levado a campo um suplemento abordando questões relacionadas ao tema saúde.

A partir de 2001 foram ampliados os quesitos do tema domicílio e substituída a investigação sobre o trabalho das crianças de 5 a 9 anos de idade por uma pesquisa suplementar sobre o trabalho das crianças e adolescentes de 5 a 17 anos de idade. Desde então, a investigação sobre o trabalho a partir de 5 anos de idade foi incorporada em definitivo ao questionário básico.

Em 2003, foi novamente realizado um suplemento sobre saúde, basicamente similar ao de 1998, permitindo a obtenção de informações comparativas sobre a 
evolução do quadro geral de acesso aos serviços de saúde e aspectos relacionados à morbidade da população brasileira ao longo do período entre as duas investigações.

\section{Abrangência geográfica}

A abrangência geográfica da investigação da PNAD vem se ampliando gradualmente. Iniciada em 1967, na área que hoje compreende o Estado do Rio de Janeiro, ao final da década a PNAD já abrangia as regiões Nordeste, Sudeste, Sul e o Distrito Federal. Em 1971, a pesquisa restringiu-se às áreas que abrangem o atual Estado do Rio de Janeiro, o Estado de São Paulo e a região Sul. Em 1973 já incorporava novamente as regiões Nordeste, Sudeste e Sul, o Distrito Federal e as áreas urbanas das regiões Norte e Centro-Oeste. Esta cobertura foi mantida até 1979.

Em 1981 a abrangência geográfica da PNAD foi mais uma vez ampliada, passando a excluir somente a área rural dos estados da região Norte. A partir de 2004 a PNAD passa a investigar também a área urbana de todos os estados da região Norte, possibilitando, portanto, obter-se um quadro mais completo da situação demográfica, social e econômica da população residente nessa região, independentemente de sua condição de residência. Com isso, a amostra domiciliar da PNAD passou a ser representativa de todo o território nacional.

\section{As informações e os estudos demográficos nas pesquisas do IBGE}

As informações demográficas contidas nas publicações e meios magnéticos dos censos demográficos, estatísticas do registro civil e Pesquisas por Amostra de Domicílios possibilitaram acompanhar todo o processo de transição demográfica que se verificou no país, com suas variações regionais e sociais.

No caso específico dos censos, desde 1940 , conforme visto, existe um conjunto de quesitos básicos sobre fecundidade e mortalidade (Quadro 1) que tornou possível acompanhar as mudanças nos níveis e padrões das componentes demográficas e na mobilidade espacial da população.

Além disso, as informações censitárias são fundamentais para a atualização das projeções populacionais para o Brasil, Grandes Regiões e Unidades da Federação, bem como para a construção das estimativas municipais de população, que se tornaram legalmente obrigatórias a cada ano, a partir de 1989.

Em relação às PNADs, nas décadas de 70 e 80 , como foi assinalado, os principais quesitos que propiciam a análise das chamadas componentes demográficas não foram investigados para todos os anos da série. Assim mesmo, o cálculo de índices demográficos como as Taxas de Fecundidade Total e de Mortalidade Infantil teve, em alguns anos em que foram elaborados, grande impacto e divulgação na sociedade e nos meios acadêmicos, inclusive na Associação Brasileira de Estudos Populacionais (Abep). Assim é que, com base na PNAD de 1976, foi detectado, pela primeira vez, o início do processo acelerado de declínio da fecundidade no Brasil. Tal tendência foi posteriormente confirmada no Censo de 1980 e pelos suplementos das PNADs de 1984 e 1986, que constataram a intensificação do declínio e sua generalização por todas as regiões e estratos sociais do país.

Nesses períodos, as informações de natureza demográfica das PNADs, embora esparsas, permitiram o acompanhamento e avaliações do processo de transição na dinâmica demográfica brasileira nos intervalos intercensitários.

A partir dos anos 90, com a incorporação do bloco demográfico ao corpo básico anual da pesquisa, os índices e taxas de fecundidade, mortalidade e mobilidade espacial da população tornaram-se também elementos de subsídio para a atualização e monitoramento das componentes demográficas implícitas nas projeções e estimativas populacionais.

Finalmente, as estatísticas do registro civil, embora ainda apresentem níveis razoavelmente elevados de sub-registro de nascimentos e óbitos em algumas regiões e unidades da Federação, revelam indicativos de que o grau de cobertura tem se 
elevado, principalmente no caso dos nascimentos, acompanhando as tendências de urbanização e institucionalização da sociedade brasileira.

Nesse sentido, os indicadores de natalidade, mortalidade e nupcialidade extraídos do registro civil vêm sendo progressivamente utilizados nas análises demográficas e na avaliação dos padrões das principais componentes demográficas

\section{Referência bibliográfica}

ALTMAN, A.M.G. e FERREIRA, C.E.C. Evolução do Censo Demográfico e Registro Civil como fontes de dados para análise de fecundidade e mortalidade no Brasil (dados coletados e estudos realizados). RBE, v. 40, n. 160, Rio de Janeiro, out./dez., 1979. usadas nas projeções e estimativas populacionais. Os problemas estão praticamente equacionados nos estados do Centro-Sul do Brasil, onde as estatísticas vitais são confiáveis do ponto de vista da cobertura e fornecem indicadores demográficos contínuos, mas é importante ressaltar que as lacunas permanecem elevadas nas regiões Norte, Nordeste e parte do CentroOeste.

SIMÕES, C.C.S. e OLIVEIRA, A.T. As Estatísticas Vitais do Registro Civil: seu histórico, situação atual e análise de alguns indicadores demográficos da década de 90 . In: IBGE/ Abep/UNFPA. Saúde no Brasil: Conceitos, Programas e Indicadores. Brasília, 2003.

\section{Abstract}

\section{IBGE and population research}

This article studies the history of the demographic censuses in Brazil, as well as civil records and the PNAD (National Survey by Household Sampling), with emphasis on the main issues investigated by each of these instruments. The important role played by the State, especially in the development of the demographic censuses, is taken up, as this factor explains their rapid development. In contrast, during their early stages civil records remained dependent on the not always stable relationships between Church and State. The increasing importance of the demographic censuses as instruments of analysis of demographic factors is gone into. The 1970 census is considered a milestone with respect to its organization, the wealth of details treated, and the reliability of the results. The role of civil society is also highlighted, as well as of the academic community and the formulators of public policies in this process. The PNAD has also played a special role in this process, as it has been carried out between censuses, with multiple investigative purposes, sometimes including demographic characteristics (migration, fertility, marital unions, etc.) and factors related to health.

Key words: Censuses. Civil records. PNAD. Population. Fertility, mortality and migration. Citizenship. Economic characteristics. 